\title{
Assessment of Residents' Understanding and Demands on Gardens in Gyeongnam Region, Korea
}

\author{
Inhea Kim ${ }^{1}$ and Keun Young Huh ${ }^{1,2 *}$ \\ ${ }^{1}$ International Garden Institute, Gyeongnam National University of Science and Technology, Jinju 52725, Korea \\ ${ }^{2}$ Department of Landscape Architecture, Gyeongnam National University of Science and Technology, Jinju 52725, Korea
}

\begin{abstract}
This study was conducted to investigate effective ways to meet social and cultural interest in and needs of gardens and gardening. A total of 191 respondents who answered they were living in Gyeongnam region in the questionnaire were selected: 102 (53.4\%) were males and 89 (46.6\%) were females. In frequency of garden visits, 45\% of the respondents answered they visited gardens once a year. Their preferred companion was family (43.6\%), followed by friends/colleagues (24.3\%). Their important motives of garden visits included admiration of gardens' scenery and ambience, pleasure in being outdoors, relaxing mentally and physically, and appreciation of plants. Relatively less important motives included understanding or educating about nature and environmental conservation, and interest in garden design and horticulture techniques. In the overall assessment of gardens and gardening, the quality of the establishment, management and operation of botanic gardens and arboreta in Gyeongnam region scored 3.32 scale, which was close to the level of 'fair.' Also, the respondents agreed at 3.91 scale that it was necessary to improve the garden creation, gardening, and garden culture. Meanwhile, many people in Gyeongnam region did not clearly understand differences between garden and public park, also had a very obscure perception of public garden. The results of importance-performance analysis (IPA) indicated that it is necessary to concentrate on directing and developing some programs such as admiration of beautiful and exotic plants, and education on garden culture including garden making and horticultural techniques.
\end{abstract}

Keywords: botanic garden, garden visit, landscape architecture, landscape garden, public park

\section{Introduction}

Although social and cultural interest in and needs of gardens have increased (Kim and Huh, 2008), many people in the domestic still have a very vague understanding and attitude towards gardens such as botanic gardens and arboretums (Kim et al., 2007). In particular, they do not seem to clearly understand differences between botanic garden and public park (Hyun et al., 2012). In fact, when traditional gardens that were intentionally restored or created are excluded, a significant number of gardens created in the domestic seem to be influenced by western culture and styles (Kim et al., 2007). This vague understanding may result from the impact of American landscape architecture and public parks created in the

This work was supported by Gyeongnam National University of Science and Technology Grant in 2018-2019.

Received: March 5, 2019, Revised: March 20, 2019, Accepted: March 27, 2019

First author: Inhea Kim, E-mail: inhyekim@hanmail.net, (1) https://orcid.org/0000-0001-9915-1623

*Corresponding author: Keun Young Huh, E-mail: sumoto@gntech.ac.kr, (1) https://orcid.org/0000-0002-3105-8745

2019 by the Society for People, Plants, and Environment. This is an Open Access article distributed under the terms of the Creative Commons Attribution Non-Commercial License (http://creativecommons.org/licenses/by-nc/4.0/) which permits unrestricted non-commercial use, distribution, and reproduction in any medium, provided the original work is properly cited. 
domestic. According to earlier studies including Addison (1745), Meason (1828), Loudon (1840) and Olmsted (1852), American landscape architecture originated in the United Kingdom. Early landscape architecture in the United Kingdom emerged from landscape gardens in the 17th and 18th centuries, including those of Charles Bridgeman, William Kent and Capability Brown, that imitated and improved the gardening style of mansions that was popular among noble families in countries like Italy, France and Netherlands. It could be understood as landscape gardening that was distinguished from conventional ornamental gardening, but pursued picturesque gardens. The concept of landscape architecture, however, was more clearly materialized and was distinguished from conventional gardens coupled with urban and regional development in the New World like the United States and Australia rather than Europe, and landscape architecture can be simply defined as the study of creating a landscape on a vast land to provide open green spaces such as parks for the general public to do outdoor activities (Beveridge and Rocheleau, 1998). Basically, gardens have been established with different concepts and purposes from parks, and, as a result, they have a different structure of space. In general, public parks or urban parks are built for outdoor activities such as sports and walking, and national parks, for the conservation of nature, while gardens are created to grow or display plants for the purpose of conservation, use or appreciation (Huh et al., 2015a). However, many people in the domestic do not clearly distinguish and understand the concept and purpose of gardens from those of parks. Therefore, it is necessary to develop effective ways to meet the growing social and cultural interest in and needs of gardens, which should begin from the correct understanding of and attitude to the concept of gardens. Returning back to the fundamental understanding of gardens, the concept of gardens needs to be separated from that of parks created based on landscape architecture and to be newly understood. Thus, this study aimed to assess the behaviors and motives of residents in Gyeongnam region, Korea of garden visits, and the establishment, management and operation of gardens, and to suggest effective ways to meet the growing social and cultural demands of gardens by analyzing the residents' perception of the concept and features of gardens, and conducting the importance-performance analysis (IPA) of visitors.

\section{Research Methods}

\section{Theoretical background}

\section{Garden concept and classification}

According to Webster's New World Dictionary, a garden is a piece of ground usually close to a house for the growing of fruits, flowers and vegetables. However, this is a classical definition, and can be limited to a private residential garden (Huh et al., 2015b). The definition of socially and culturally created concepts needs to be renewed to meet changes over time. Therefore, public gardens such as botanic gardens and arboretums cannot be defined as 'a piece of ground usually close to a house for the growing of fruits, flowers and vegetables' as mentioned above.

In 1989, the International Union for Conservation of Nature (IUCN), the Botanical Gardens Conservation Secretariat (BGCS), and the World Wildlife Fund (WWF) defined botanic garden as a garden open to the public and where the plants are labelled (Heywood, 1989). In 2000, the Botanic Gardens Conservation International (BGCI) adopted a new definition with clearer understanding of botanic gardens. The BGCI defined it as an institution that holds documented collections of living plants for the purposes of scientific research, conservation, display, and education (Wyse Jackson and Sutherland, 2000). The first and latter definition show that a concept formed in the social and cultural context of the one time needs to be re-defined to meet the needs of the other times, and that, in the same context, the concept of gardens commonly used in the fields of horticulture, landscape, and forestry in Korea today needs to be re-defined as well (Huh et al., 2015b).

Gardens are divided into private or public gardens depending on whether they were created to grow plants for the 
purpose of personal or public enjoyment and profit (Huh et al., 2015a). A private garden is defined as a piece of ground usually close to a house for the growing of flowers, vegetables, herbs, fruits or ornamental plants. A public garden is defined as a place or an institute that has various values for the public and grows plants for one or multiple purposes among scientific research, conservation, display and education, and public gardens also include botanic gardens, arboretums and private gardens open to the public. Benfield (2013) partially revised and supplemented the classification of public gardens suggested by Wyse Jackson and Sutherland (2000) as follows: multi-purpose garden, ornamental garden, historical garden, conservation garden, university garden, combined botanic and zoological garden, agrobotanical and germplasm garden, alpine or mountain garden, natural or wild garden, horticultural garden, thematic garden, and community garden. Huh et al. (2015b) also partially revised and supplemented the classification of public gardens suggested by Benfield (2013) and Wyse Jackson and Sutherland (2000), and distinguished between community garden and allotment garden, and classified and defined gardens according to the purpose of use and plant materials considering the circumstances of gardens in Korea today. First of all, depending on the purpose of use, gardens were divided into multi-purpose garden, ornamental garden, conservation garden, university garden, therapeutic garden, thematic garden, festive garden, community garden, allotment garden, private open garden, etc. Depending on plant materials, they were divided into botanic garden, arboretum, thematic garden, etc. and their subordinate relationship was defined as 'botanic garden > arboretum > thematic garden'or if arboretums are not included, as 'botanic garden > thematic garden.'

\section{Differences between public garden and public park}

A park is defined in Korea as a vast area created for the purpose of enjoyment and relaxation; a natural space or an artificially-created landscape space for welfare that is operated and managed by a national or local government for the purpose of contributing to the improved recreational and emotional life of citizens or residents; or a vast area, as a kind of public green space, created for people to relax, exercise and play (Act on urban parks, 2018). The first park in Great Britain was "English Deer Parks" created for kings and nobles in the Middle Age to hunt deers. Parks back then had walls and thick hedges around them in order to limit the access of people. Such parks had developed into privately-owned parks with landscape beauty that were located near mansions and country houses since the 16th century. The natural landscape beauty of such parks was upgraded by English gardeners like Capability Brown. As cities were overpopulated, these privatelyowned parks turned into places for the public, and the parks started to be recognized as a public area set aside for natural conservation by a city or a village during the Industrial Revolution. In the United States, parks, in general, referred to public parks or urban parks, and a public park is defined in the Municipal Code of Inglewood, California as a public playground, public recreation center or area, and other public areas, created, established, designated, maintained, provided or set aside by the City, for the purposes of public rest, play, recreation, enjoyment or assembly and all buildings, facilities and structures located thereon or therein (Inglewood Municipal, 2019).

Among the functions of public gardens, opening to the public for the display and education of plants may be similar to that of public parks in a manner to provide enjoyment and rest to the public or to contribute to the improvement of the residents' health recreation and emotional life (Huh et al., 2015b). Consequently, public gardens can be understood as similar to public parks. In terms of the fundamental purpose of creation, however, there are distinct differences between public gardens and public parks. Public gardens are created for the purposes of scientific research, conservation, display, and education on plants, while public parks are created for residents living in cities or villages to enjoy recreation and relaxation. For this reason, public gardens such as Kew Garden in Great Britain and National Arboretum in Korea can be located within or near public parks or public green spaces, but their values, purposes and operation are different from those of public parks. For instance, Auckland Botanic Gardens and Totara Park in New Zealand are adjacent to each other, 
which is a good case that shows that botanic gardens are recognized separately from parks (Huh et al., 2015b). Auckland Botanic Gardens have several collections including New Zealand Native Plant Collection, Edible Garden, New Zealand Endangered Plant Garden, Perennial Garden, Palm Garden, Gondwana Arboretum, New Zealand Native Forest, Magnolia Garden, Camellia Garden, Spring Blossom Valley, South African Garden, Rock Garden, Conifers, Herb Garden, Salvia Garden, etc. while Totara Park is composed of walkway, swimming pool, stream and forest trail, wildlife, barbecue area, tennis courts, playground, horseriding, mountain bike tracks, etc.

\section{Gardening and garden tourism}

Gardening includes those to design and create gardens on the ground, plant garden plants, manage or operate gardens, and enjoy leisure activities such as appreciating, socializing and relaxing within gardens, and to visit gardens or garden centers for the purpose of obtaining materials and information (Huh et al., 2015b). In other words, gardening in 21C includes not only conventional garden activities, but also garden tourism. Benfield (2013) defined garden tourism simply as travel away from one's normal domicile to purchase, view, or spend reflective or educational time in an area of horticultural creation, most often with the moniker "garden."

Botanic Gardens Conservation International estimated that internationally, visits to botanic gardens and arboretums numbered approximately 250 million per year (Ballantyne et al., 2008). The motives of garden visitors include appreciation of the aesthetic and rare qualities of plants; interest in garden design and landscaping techniques used in different periods of history; admiration of gardens' scenery and 'ambience'; and pleasure in being outdoors (Connell and Meyer, 2004). The peace and tranquillity of gardens and the spiritual and restorative benefits have also been identified as features that attract people to public gardens (Bennett and Swasey, 1996; Australia's botanic gardens, 2009; Darwin-Edwards, 2000). There are other reasons to visit gardens including recreation, play, social interaction (Bennett and Swasey, 1996; Darwin-Edwards, 2000), desire to get inspiration (Bennett and Swasey, 1996), and opportunities for relaxing and reading (Bennett and Swasey, 1996; Crilley and Price, 2005).

Meanwhile, Ballantyne et al. (2008) mentioned that botanic gardens in particular are traditionally associated with environmental conservation and education, and they typically contain collections of plants for education, scientific purposes and display. Botanic gardens around the world started to play a greater role in educating the public about issues related to environmental changes and conservation on earth (Mintz and Rode, 1999; Willison, 1997). The form of these gardens are usually informal and aesthetically, and are thus carefully located to improve interactions among plants, animals and people (Jones, 2000). Botanic gardens have the potential to provide informal education experiences that can not only promote the importance of plants, habitat and conservation, but also affect the values, attitude and behaviors of visitors (Willison, 1997). To do this effectively, Ballantyne et al. (2008) mentioned that they require well-designed interpretation that communicates the importance of preserving plants for the future well-being of the planet.

\section{Selecting the subjects and questionnaire design}

To assess the residents' understanding and demands on gardens in Gyeongnam region, Korea, subjects were selected among those living in Gyeongnam region. The questionnaire used to select subjects included a question about their residence, and the survey was conducted within Gyeongnam region including Jinju city and Changwon city. Out of the collected questionnaire sheets, those who answered that they were living in Gyeongnam region were selected as the subjects of this study. As shown in Table 1, the questionnaire included one question about residence to select subjects and two questions about demographic background, which were designed based on a nominal scale. Two questions about the 
Table 1. Scheme of questionnaire design

\begin{tabular}{|c|c|c|}
\hline & Category & $\begin{array}{c}\text { No. of } \\
\text { questions }\end{array}$ \\
\hline \multicolumn{2}{|l|}{ Current residence } & 1 \\
\hline Demographical background & $\begin{array}{l}\text { Gender } \\
\text { Age }\end{array}$ & 2 \\
\hline Behavior of garden visit & $\begin{array}{l}\text { Frequency of visits } \\
\text { Preferred companion }\end{array}$ & 2 \\
\hline Motives of garden visits & & 7 \\
\hline Overall assessment of garden and gardening & $\begin{array}{l}\text { Construction, maintenance, and operation } \\
\text { Necessity of improvement in garden creation, gardening, garden culture, etc. }\end{array}$ & 2 \\
\hline Perception of gardens & Level of similarity between garden, public park, botanic garden and public garden & 6 \\
\hline \multicolumn{2}{|c|}{ Pre-visit importance of Suncheonman National Gardens, Bansung arboretum, etc. } & 12 \\
\hline \multicolumn{2}{|c|}{ Post-vist performance of Suncheonman National Gardens, Bansung arboretum, etc. } & 12 \\
\hline
\end{tabular}

behavior of garden visit were included, and the frequency of visits and preferred companion were designed based on a ratio scale and nominal scale respectively. Based on Ballantyne et al. (2008) and Connell (2004), the questionnaire included seven questions about the motives of garden visits and two questions about the assessment of gardens they visited, which were designed based on a 5-point Likert scale ( $1=$ strongly disagree to $5=$ strongly agree). To assess the subjects' perception of the concept and characteristics of gardens, questions about their perception of four terms including garden, public park, botanic garden and public garden were included, and similarities between the results were analyzed using paired comparison. These questions were evaluated using a 7-point Likert scale as follows. Subjects were instructed to give 1 point if they thought there was a high similarity between the terms, and 7 points if they thought there was no similarity between them (Kwon et al., 2016). Based on Ballantyne et al. (2008), the questionnaire included 12 questions about the pre-visit importance and post-visit performance of Suncheonman National Garden, Banseong Arboretum, etc. located therein or thereby, and they were evaluated using a 5 -point Likert scale $(1=$ strongly disagree to $5=$ strongly agree).

\section{Questionnaire survey and statistical analysis}

A total of 250 questionnaire sheets were distributed in Gyeongnam region including Jinju city and Changwon city between June and August, 2018, and, out of the collected answer sheets, 191 sheets of those who answered they were living in Gyeongnam region were analyzed in this study. The demographic background of the selected subjects and the behaviors of garden visit were analyzed using frequency analysis, and the motives of garden visits and the assessment of gardens and gardening were analyzed using descriptive statistical analysis. To assess their perception of the concept and characteristics of gardens, similarities in the perception of four terms including garden, public park, botanic garden and public garden were analyzed using multi-dimensional scaling (MDS). Multi-dimensional scaling is a statistical technique that assumes that respondents simplify and memorize complex relationships between objects within their psychological space, and that identifies their relative distance within the psychological space using questions about similarities between the objects and extracts the distance on a perceptual map (Lee and Lim, 2018). When the distance between two objects is identified, those that have a low similarity are located far from each other, and those that have a high simi- 
larity are located close to each other using the concept of the Euclidean distance (Bae et al., 2010). The goodness-of-fit of the similarity perception model about the four terms was measured as a stress value. A stress value shows the level of discrepancy in dispersion, meaning an error between the actual distance and the measured distance between the objects. The value is between 0 and 1 , and when the two distances are perfectly matched, the value is 0 , indicating that the smaller the estimated distance, the higher the accuracy (Kim and Cho, 2017). The pre-visit importance and post-visit performance of Suncheonman National Garden, Banseong Arboretum, etc. located therein or thereby were analyzed using importanceperformance analysis (IPA). IPA is a technique that was first developed by Martilla and James (1977) to improve the service quality of car dealers and has been widely used in various fields including business administration, marketing and tourism (Jeong and Seo, 2010; Oh, 2001). IPA is used in the tourism industry to simultaneously compare and analyze how consumers perceive and assess the importance-performance of important attributes that a product or service contains (Kim, 2008). IPA uses a two-dimensional grid divided into four quadrants, and the first quadrant shows high importance and high performance; the second quadrant, high importance and low performance; the third quadrant, low importance and low performance; and the fourth quadrant, low importance and high performance (Kim and Kim, 2016). Variables in the first quadrant indicate that their level needs to be maintained ('keep up the good work'), and those in the second quadrant indicate that they need to be improved preferentially ('concentrate here'). Those in the third quadrant indicate that they have low priorities ('low priority'), and those in the fourth quadrant can be interpreted as a strategic timing to avoid overkill ('possible overkill') (Jeong and Seo, 2010).

\section{Results and Discussion}

\section{Demographic background}

This study examined whether the composition of respondents well reflected demographic characteristics through an analysis on the characteristics of samples (Kwon et al., 2016). A total of 191 respondents who answered they were living in Gyeongnam region were analyzed, and the number of males was $102(53.4 \%)$ and that of females was 89 (46.6\%), which was similar to the population ratio in the region (males, 50.7\% and females, 49.3\%) (Gyeongsangnamdo, 2018). The number of those in the $20 \mathrm{~s}$ was the highest (90 people, $47.4 \%$ ), followed by those in the 40 s and 50 s (32 people, 16.8\%) (Table 2).

\section{Behaviors and motives of garden visits}

The number of those who visited gardens once a year was the highest ( 86 people, $45.0 \%$ ), followed by those who visited twice a year (48 people, $25.1 \%$ ) (Table 3). The number of those who visited gardens less than once a year was 20 people (10.5\%). According to the results of a study on the characteristics and motives of garden visitors in the United Kingdom (Connell, 2004), the share of those who visited gardens at least once a month was $47.1 \%$; that of those who visited gardens several times a year, 47.7\%; and that of those who visited gardens less than once a year, 5.2\%. Compared to the results, the frequency of garden visits surveyed in Gyeongnam region is very low. The number of those who answered they preferred family members as a companion was the highest (79 people, $43.6 \%$ ), followed by those who answered they preferred friends/colleagues (44 people, 24.3\%) and loved one (43 people, 23.8\%). However, the number of those who answered club/group (7 people, 3.9\%) and alone (8 people, 4.4\%) was low. Connell (2004) showed that those who preferred loved one, family members and alone accounted for $46.1 \%, 28.2 \%$ and $14.2 \%$ respectively. Ballantyne et al. (2008) showed that those who preferred family members, loved one and alone accounted for $61 \%, 21 \%$ and $2 \%$ respectively. Compared to the 
Table 2. Demographic background of respondents

\begin{tabular}{llrr}
\hline Variable & & Frequency & Percent $(\%)$ \\
\hline \multirow{3}{*}{ Gender } & Male & 102 & 53.4 \\
& Female & 89 & 46.6 \\
& Total & 191 & 100.0 \\
& $20 \mathrm{~s}$ & 90 & 47.4 \\
& $30 \mathrm{~s}$ & 22 & 11.6 \\
Age & $40 \mathrm{~s}$ & 32 & 16.8 \\
& $50 \mathrm{~s}$ & 32 & 16.8 \\
& $60 \mathrm{~s}$ & 12 & 6.3 \\
& $70+$ & 2 & 1.1 \\
& Total & 190 & 100.0 \\
\hline
\end{tabular}

Table 3. Frequency of garden visits and preferred companion for visiting botanic garden, arboretum, etc.

\begin{tabular}{llcc}
\hline Variable & & Frequency & Percent $(\%)$ \\
\hline & Less than once a year & 20 & 10.5 \\
Once a year & 86 & 45.0 \\
2 times a year & 48 & 25.1 \\
Frequency of visits & 3 times a year & 18 & 9.4 \\
& 4 times a year & 5 & 2.6 \\
& 5 times a year & 10 & 5.2 \\
& More than 10 times a year & 4 & 2.1 \\
& Total & 191 & 100.0 \\
& Family & 79 & 43.6 \\
Preferred companion & 44 & 24.3 \\
& Friend/colleague & 43 & 23.8 \\
& Loved one & 7 & 3.9 \\
& Club/group & 8 & 4.4 \\
\hline & Alone & 181 & 100.0 \\
\hline
\end{tabular}

results of these two studies, garden visitors in Gyeongnam region were found to prefer visiting gardens with family members or friends/colleagues.

To the motives of garden visits, the mean value of 'admiration of gardens' scenery and ambience'was the highest (4.10), followed by 'pleasure being in outdoors (4.02)' (Table 4). Meanwhile, the mean value of 'understanding and education about nature and environmental conservation' was the lowest (3.44), and that of 'interest in garden designs and horticultural techniques' was the second lowest (3.70). Crilley and Price (2005) conducted a study on Adelaide Botanic Gardens and found that $57 \%$ of the respondents chose 'viewing plants' as one of the three important reasons why they visited the garden, but that only $15 \%$ answered their motive was to 'learn about plants.' In a study on Mt. Coot-tha Botanic 
Gardens, Ballantyne et al. (2008) showed similar results as follows. Respondents answered that they mostly visited the botanic garden to enjoy oneself; to admire the garden's scenery; to spend quality time with family or friends; and to enjoy being outdoors/in nature, while they showed a relatively low level of interest in and commitment to conservation issues. Indeed, it is generally accepted that the majority of visitors to botanic gardens do not come to learn per se (DarwinEdwards, 2000). The results of this study also showed that the major motives of residents living in Gyeongnam region for visiting gardens were 'admiration of gardens' scenery and ambience,' 'pleasure in being outdoors,' 'relaxing mentally and physically,' and 'appreciation of plants,' and that 'understanding or education about nature and environmental conservation' and 'interest in garden design and horticulture techniques' were relatively less important.

\section{Assessment of gardens and gardening within or nearby Gyeongnam region}

The mean value of the quality of the construction, maintenance and operation of botanic gardens and arboreta therein or thereby was 3.32, close to 'fair,' while that of the necessity of improvement in garden creation, gardening, garden culture, etc. was 3.91, close to 'agree' (Table 5). These results indicate that the quality of the construction, maintenance and operation of botanic gardens and arboreta in the region is not good, and that, for the reason, the garden creation, gardening and garden culture need to be improved.

\section{Perception of the concept and characteristics of gardens}

Using multi-dimensional scaling (MDS), similarities in the perception of four terms including garden, public park, botanic garden and public garden were analyzed using paired comparison, and the results were displayed on the perceptual map in Figure 1. The measured stress value was .175, indicating that the model is between fair and poor (Kruskal and Wish, 1978). The distance between garden, public park, botanic garden and public garden on the perceptual map was

Table 4. Motives of garden visits

\begin{tabular}{lrr}
\hline Variable & $\mathrm{M}$ & $\mathrm{SE}$ \\
\hline Appreciation of plants & 3.84 & 0.06 \\
Interest in garden design and horticulture techniques & 3.70 & 0.07 \\
Admiration of gardens' scenery and ambience & 4.10 & 0.05 \\
Pleasure in being outdoors & 4.02 & 0.06 \\
Relaxing mentally and physically & 3.88 & 0.06 \\
Recreation, playing games and social interaction with family or friends & 3.79 & 0.07 \\
Understanding or education about nature and environmental conservation & 3.44 & 0.06 \\
\hline
\end{tabular}

Note. 5 -point Likert scale answers ranged from $1=$ strongly disagree to $5=$ strongly agree.

Table 5. Overall assessment of gardens, gardening and garden culture in Gyeongnam region

\begin{tabular}{lll} 
Variable & M SE & \multicolumn{1}{l}{ S } \\
\hline Quality of construction, maintenance and operation of botanic gardens, arboreta, etc. in Gyeongnam region & 3.32 & 0.05 \\
Necessity of improvement in garden creation, gardening, garden culture, etc. & 3.91 & 0.05 \\
\hline
\end{tabular}

Note. 5 -point Likert scale answers ranged from $1=$ strongly disagree to $5=$ strongly agree. 
analyzed, and the four terms were not distinctly close to each other (Figure 1), which indicates that respondents have a vague understanding of and attitude toward the four terms. From garden, public park was the relatively most distant, and public garden was the second most distant. Meanwhile, botanic garden was the relatively closest to garden. Public garden was the relatively closest to public park, and botanic garden was the second closest. In fact, since the characteristics of garden differ from those of public park, they need to be located relatively farthest from each other on the map, while garden needs to be located relatively very close to botanic garden and public garden due to their common and similar characteristics. Moreover, botanic garden is included in the category of public garden, and thus they need to be located relatively very close to each other. The reason is that garden is the highest concept that covers private garden and public garden, and botanic garden and arboretum are included in the category of public garden. In addition, public park is the relatively most differentiated term from garden. As a result, while social and cultural interests in and demands of gardens are increasing, many people in Gyeongnam region still have a very vague understanding of and attitude toward gardens. Hyun et al. (2012) mentioned about concerns over visitors' tendency to perceive arboretum as a public park, and, in particular, they do not clearly distinguish and understand differences between garden and public park. Moreover, people tend to very vaguely perceive the term, public garden. This vague perception can be attributed to the facts that landscape architecture developed in the United States has significantly affected public parks or urban parks created in Korea, that the understanding of European garden designs and culture relatively still has remained at the basic level, and that, as a result, our perception had created gardens or public parks with a vague identity or definition (Kim et al., 2007).

\section{Importance-performance analysis of garden visits}

The results of the importance-performance analysis (IPA) of the pre-visit importance and post-visit performance of Suncheonman National Garden, Banseong Arboretum, etc. are as shown in Figure 2. In Quadrant 1 that shows high importance and high performance, a total of three variables including 'admiration of gardens' scenery and ambience (6), 'various plant exhibition events such as rose festival and chrysanthemum festival (7)' and 'walking trails and resting

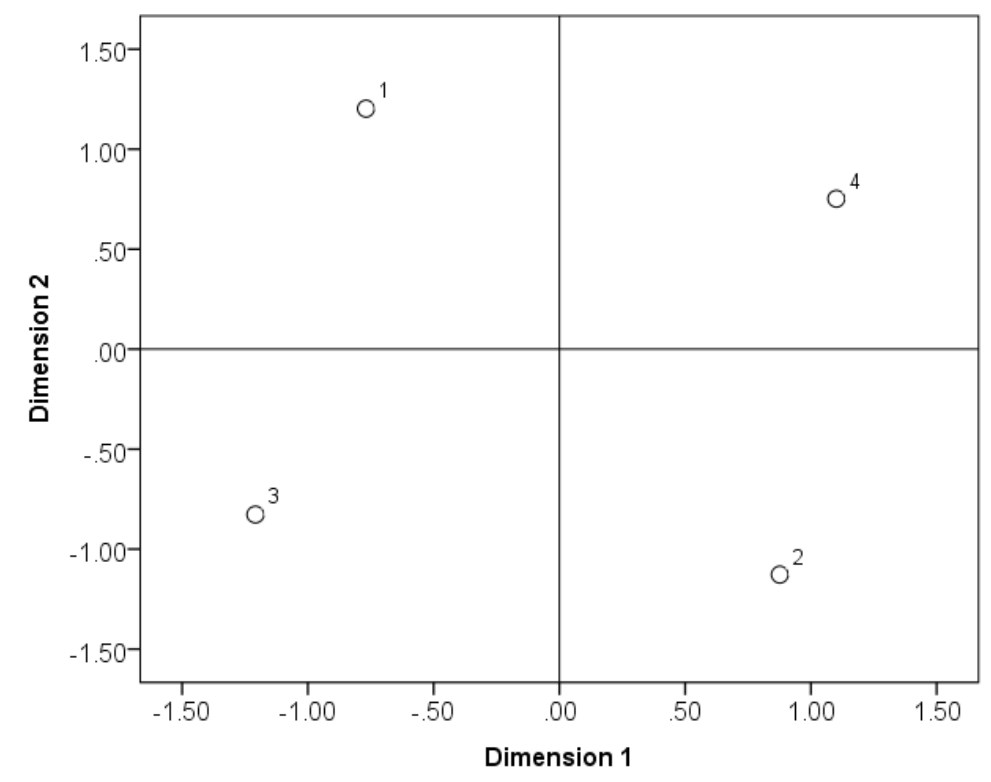

Figure 1. Perceptual map for four terms: 1 = garden; 2 = public park; 3 = botanic garden; 4 = public garden . 


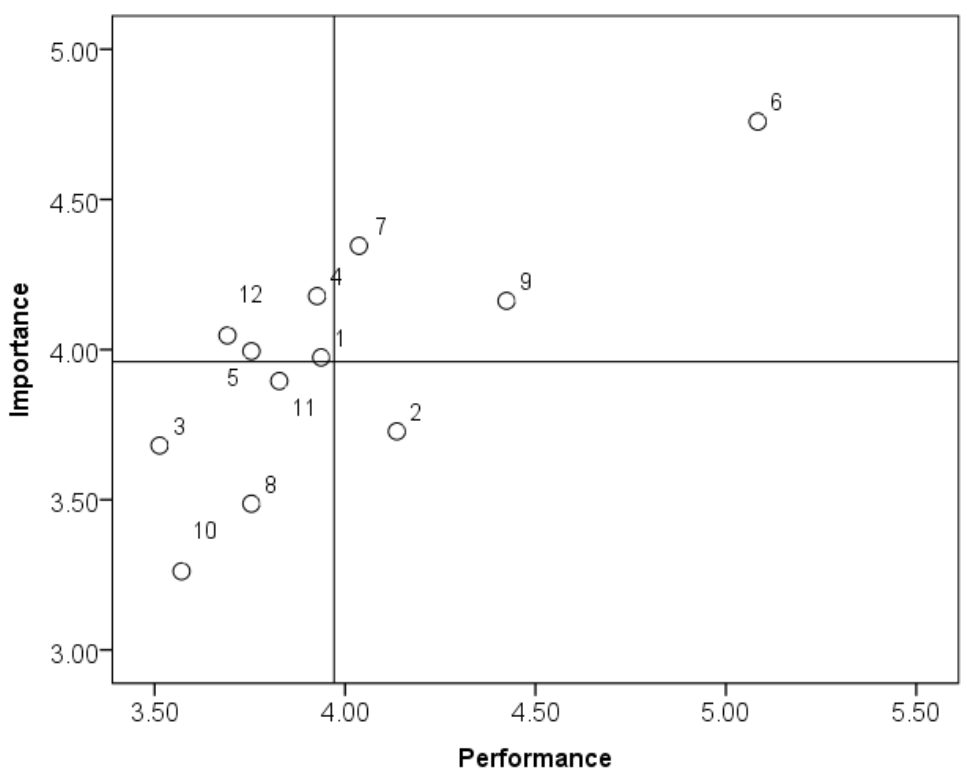

Figure 2. Importance-performance analysis of garden visits: 1 = conservation of plants and natural resources; 2 = research for conservation and utilization of plants; 3 = education on conservation of plants and natural resources; $4=$ education on garden culture including garden making, horticultural techniques, etc.; $5=$ admiration of beautiful and exotic plants; 6 = admiration of gardens' scenery and ambience; 7 = various plant exhibition events such as rose festival and chrysanthemum festival; $8=$ various culture events such as concerts, exhibitions and performances; $9=$ walking trails and resting spaces for relaxing mentally and physically; $10=$ facilities such as cafes and restaurants for social interaction; 11 = green spaces such as lawns for outdoor activities; $12=$ accessibility of easy-to-visit location, parking, etc.

spaces for relaxing mentally and physically (9)' were located. Motives of garden visits include 'admiration of gardens' scenery and ambience' (Connell and Meyer, 2004). As gardens have informal forms in general and give aesthetic pleasure to the public, they are located to improve interactions among plants, animals and people (Jones, 2000). For this reason, both the importance and performance of admiration of the beauty of gardens' scenery and ambience were high. Various plant exhibition events such as rose festival and chrysanthemum festival showed high performance, which can be attributed to improved cultural levels, attractive exhibition techniques and quality programs. As most gardens not only in Gyeongnam region but also in other regions in the domestic are created based on the similar concept of public parks, the performance of 'walking trails and resting spaces for relaxing mentally and physically' was high.

In Quadrant 2 that shows high importance and low performance, a total of four variables including 'conservation of plants and natural resources (1), 'education on garden culture including garden making, horticultural techniques, etc. (4),' 'admiration of beautiful and exotic plants (5)' and 'accessibility of easy-to-visit location, parking, etc. (12)' were located. Public gardens such as botanic gardens and arboreta are a kind of institutes that research and provide education on plants and natural resources, and conserve and display them, and they not only promote the importance of plants, habitat and conservation, but also have the potential to provide informal education experiences that can affect the values, attitude and behaviors of visitors (Willison, 1997; Wyse Jackson and Sutherland, 2000). Admiration of beautiful and exotic plants, and education on garden culture including garden making, horticultural techniques, etc. were reported as the main motives of those who visited gardens in the United Kingdom (Connell and Meyer, 2004). They are similar to the motives of garden visitors in Gyeongnam region. However, it was found that the quality of exhibition techniques and programs related to conservation of plants and natural resources, and exhibitions of beautiful and exotic plants was low, and that visitors 
were not satisfied with education programs for the enjoyment of gardening and garden culture. Gardens of this quality are, in fact, recognized by visitors as places similar to public parks, and even as less attractive places than public parks. Meanwhile, despite the beautiful natural scenery and ambience of gardens, the accessibility of these gardens was not satisfiable.

In Quadrant 3 that shows low importance and low performance, a total of four variables including 'education on conservation of plants and natural resources (3),' 'various cultural events such as concerts, exhibitions and performances (8),' 'facilities such as cafes and restaurants for social interaction (10)' and 'green spaces such as lawns for outdoor activities (11)' were located. Visitors in Gyeongnam region also showed low importance and performance of education on conservation of plants and natural resources. Ballantyne et al. (2008) pointed out that botanic gardens have long been related, in particular, to environmental conservation and education, and even have put focus on education for the public in order to receive support for their effort to conserve plants, but that visitors showed a relatively low interest in and commitment to issues related to conservation, and gave a lower point to education and discovery as a motive for visiting gardens. Therefore, it is necessary to carefully consider how educational activities in which botanic gardens put focus on conservation should be designed and improved. Both the importance and performance of various cultural events such as concerts, exhibitions and performances, facilities such as cafes and restaurants for social interaction, and green spaces such as lawns for outdoor activities were low. Compared to the United Kingdom and Australia, the Gyeongnam region has not provided various cultural activities in gardens due to differences in lifestyles, accessibility, etc. and thus it is necessary to increase accessibility to gardens and distribute various garden cultures.

In Quadrant 4 that shows low importance and high performance, one variable, that is, 'research for the conservation and utilization of plants (2)' was located. Respondents were found to think that research for conservation and utilization of plants was not important, but that its performance was high. Botanic gardens are a kind of institutes that collect and keep documents about living plants for scientific research, conservation, display and education (Wyse Jackson and Sutherland, 2000), and put focus on education for the public to receive support for their effort to conserve plants (Ballantyne et al., 2008), but visitors in Gyeongnam region were found to think that research for conservation and utilization of plants was not important, and that excessive efforts have been put into it. In this regard, it will be necessary to examine what type of visitors accept these messages.

Based on the results of Martilla and James (1977), 'admiration of gardens' scenery and ambience (6),' 'various plant exhibition events such as rose festival and chrysanthemum festival (7),' and 'walking trails and resting spaces for relaxing mentally and physically (9)'can be classified into the category of 'keep up the good work,' and thus their level needs to be maintained. 'Conservation of plants and natural resources (1),' 'education on garden culture including garden making, horticultural techniques etc. (4),' 'admiration of beautiful and exotic plants (5),' and 'accessibility of easy-to-visit location, parking, etc. (12)' can be classified into the category of 'concentrate here,' and thus they need to be improved preferentially. 'Education on conservation of plants and natural resources (3), 'various cultural events such as concerts, exhibitions and performances (8),' and 'facilities such as cafes and restaurants for social interaction (10)' are 'low priorities.' 'Research for conservation and utilization of plants (2)' can be interpreted as a strategic timing to avoid overkill (Jeong and Seo, 2010).

\section{Conclusion}

Effective ways to meet the growing social and cultural interest in and demands of gardens need to start from the correct understanding of and attitude toward the conception of gardens. In this regard, this study analyzed the behaviors and 
motives of residents in Gyeongnam region for garden visit; the assessment of gardens and gardening in the region; and their perception of the concept and characteristics of gardens, and also conducted importance-performance analysis (IPA) of garden visit.

First, a total of 191 respondents living in Gyeongnam region for visiting gardens were surveyed, and their behaviors and motives of garden visits were analyzed. Males and females accounted for $53.4 \%$ and $46.6 \%$ respectively, and the share of those who visited gardens once a year was the highest (45.0\%), showing a very low frequency. Subjects preferred to visit gardens with family members $(43.6 \%)$ or friends/colleagues $(24.3 \%)$. Their major motives of garden visits included admiration of gardens' scenery and ambience, pleasure in being outdoors, relaxing mentally and physically, appreciation of plants, while understanding or educating about nature and environmental conservation, and interest in garden design and horticulture techniques were found to be relatively less important. The results of the assessment of gardens and gardening showed that the quality of the construction, maintenance and operation of botanic gardens and arboreta in or near Gyeongnam region was low, and that, for the reason, gardening and garden culture needed to be improved.

Subjects' perception of the concept and characteristics of gardens was also assessed, and many people in Gyeongnam region were found to have a very vague understanding of and attitude toward gardens. In particular, they did not clearly distinguish differences between garden and public park, and they even very vaguely perceived the term, public garden. Based on the results of importance-performance analysis (IPA) of garden visit, admiration of gardens' scenery and ambience, various plant exhibition events such as rose festival and chrysanthemum festival, and walking trails and resting spaces for relaxing mentally and physically were classified into the category of 'keep up the good work,' while conservation of plants and natural resources, education on garden culture including garden making, horticultural techniques, etc., admiration of beautiful and exotic plants, and accessibility of easy-to-visit location, parking, etc. were classified into the category of 'concentrate here.' Education on conservation of plants and natural resources, various cultural events such as concerts, exhibitions and performances, and facilities such as cafes and restaurants for social interaction were found to be 'low priorities.' Research for conservation and utilization of plants was classified into the category of 'possible overkill.'

One of the effective ways to meet the growing social and cultural interest in and demands of gardens is to improve people's understanding of and attitude toward the differentiated concept of gardens from public parks, gardening and garden culture. In creating and operating public gardens such as botanic gardens and arboreta, it is necessary to focus on directing and developing programs such as admiration of beautiful and exotic plants, and education on garden culture including garden making, horticultural techniques etc. When creating a new botanic garden, it is necessary to improve accessibility of easy-to-visit location, parking, etc. and those that were found to be low priorities including various culture events such as concerts, exhibitions and performances, and facilities such as cafes and restaurants for social interaction need to be considered as well. Lastly. in terms of research for conservation and utilization of plants, it will be necessary to consider post occupancy evaluation (POE) not only for effective education, public relations and feedback, but also for receiving support from the public.

\section{References}

Act on urban parks, green areas, etc. Act No. 15675. 2018. Retrieved from

http://www.law.go.kr/lsInfoP.do?lsiSeq=203772\&efYd=20181213\#0000

Addison, J. 1745. Remarks on several parts of Italy, \&c in the years 1701, 1702, 1703 (1st ed.). London, England: J. and R. Tonson.

Australia's botanic gardens. 2009, May 7. Retrieved from https://www.anbg.gov.au/chabg/abg/index.html 
Bae, H.W., K.H. Kwon, M.N. Moon, and H.S. Moon. 2010. Multidimensional scaling analysis on the images of special academics. J. Korean Data Inf. Sci. Soc. 21(1):11-20.

Ballantyne, R., J. Packer, and K. Hughes. 2008. Environmental awareness, interests and motives of botanic gardens visitors: Implications for interpretive practice. Tour. Manag. 29(3):439-444.

https://doi.org/10.1016/j.tourman.2007.05.006

Benfield, R.W. 2013. Garden tourism. Boston, MA: CAB International.

Bennett, E.S. and J.E. Swasey. 1996. Perceived stress reduction in urban public gardens. HortTechnology 6(2):125-128.

Beveridge, C.E. and P. Rocheleau. 1998. Frederick Law Olmsted: Designing the American landscape. New York: NY: Universe.

Connell, J. 2004. The purest of human pleasures: The characteristics and motivations of garden visitors in Great Britain. Tour. Manag. 25(2):229-247. https://doi.org/10.1016/j.tourman.2003.09.021

Connell, J. and D. Meyer. 2004. Modelling the visitor experience in the gardens of Great Britain. Curr. Issues Tour. 7(3): 183-216. https://doi.org/10.1080/13683500408667979

Crilley, G. and B. Price. 2005. The Adelaide Botanic Gardens visitor service quality survey. Adelaide, Australia: Centre for Environmental and Recreational Management, University of South Australia.

Darwin-Edwards, I. 2000. Education by stealth: The subtle art of educating people who didn't come to learn. Roots 20: $37-40$.

Gyeongsangnamdo. 2018. Gyeongsangnam-do population and households at the end of August 2018. Monthly Gyeongnam population Report. Retrieved from http://www.gyeongnam.go.kr/data/board/view.gyeong?boardId=BBS_0000257\& menuCd=DOM_000002903004000000\&paging $=$ ok\&startPage $=1 \&$ dataSid $=4084082$

Heywood, V.H. 1989. The botanic gardens conservation strategy/prepared for IUCN and WWF. Gland, Switzerland: World Wildlife Fund and International Union for the Conservation of Nature and Natural Resources.

Huh, K.Y., I. Kim, E.J. Jo, J.H. Ki, J.I. Song, K.C. Son, and K.S. Hur. 2015a. Interpretation of related laws and suggestions for securing initiative of horticulture in the field of gardens (pp. 15-16). Wanju, Korea: National Institute of Horticultural and Herbal Science, Rural Development Administration.

Huh, K.Y., I. Kim, E.J. Jo, J.M. Kim, J.H. Ki, J.I. Song, K.C. Son, W.S. Kim, and A.K. Lee. 2015b. Plan of fostering and developing garden industry. Sejong, Korea: Ministry of Agriculture, Food and Rural Affairs.

Hyun, J.O., Y.S. Kim, H.T. Shin, S.K. Kang, J.I. Kim, J.G. Kim, J.W. Yoon, and M.H. Yi. 2012. The user's satisfactory analysis of botanical gardens and arboreta in Korea. J. Korean Inst. For. Recreat. 16(1):13-24.

Inglewood Municipal. 2019. Definition of public park (Section 5-56). Inglewood municipal code, chapter 5 offenses, miscellaneous, article 3. park regulations. Retrieved from

https://www.qcode.us/codes/inglewood/view.php?topic=5-3-5_56\&frames=on

Jeong, C. and Y.S. Seo. 2010. Re-examination of Importance-Performance Analysis (IPA) used in tourism studies in Korea. J. Tour. Stud. [Hanyang University] 22(1):119-137.

Jones, D.M. 2000. Making connections with the earth. In: Reaching out to the garden visitor (pp. 7-12). Kennett Square, PA: American Association of Botanical Gardens and Arboreta.

Kim, H. and J. Cho. 2017. A study on the cognition distance of separately shelved items by multi-dimensional scaling analysis in children's libraries. J. Korean Soc. Inf. Manag. 34(1):51-71.

Kim, I. and K.Y. Huh. 2008. The beginning and changes of cottage garden style in New Zealand. J. Korean Soc. People Plants Environ. 11(4):83-96.

Kim, I., K.Y. Huh, H.C. Kang, Y.B. Sagon, and M. Wrigley. 2007. A study on history and culture of 19C English and Australasian cottage garden. J. Korean Soc. People Plants Environ. 10(2):26-43.

Kim, S.W. 2008. Attractiveness assessment of Mt. Kumgang Tourists' destination using importance-performance analysis. J. Tour. Stud. [Hanyang University] 20(1):101-115.

Kim, Y.S. and Y.S. Kim. 2016. Research on the importance and satisfaction of selection attribute for tourism destination, using importance-performance analysis: focusing on visitors to Jeollabuk-do. J. Tour. Leis. Res. 28(12):25-41. 
Kruskal, J.B. and M. Wish 1978. Multidimensional scaling. Sage University Paper Series on Quantitative Applications in the Social Sciences. Newbury Park, CA: Sage Publications. https://doi.org/10.4135/9781412985130

Kwon, Y., K. Jang, and I.G. Jang. 2016. Multidimensional scaling analysis of inter-regional public transit services: Focusing on inter-regional railways. J. Korean Soc. Railway 19(2):243-250.

Lee, H.S. and J.H. Lim. 2018. SPSS 24 manual. Seoul: Jibhyeonjae.

Loudon, J.C. 1840. The landscape gardening and landscape architecture of the late Humphry Repton, Esq. London, England: Longman \& Co.

Martilla, J.A. and J.C. James. 1977. Importance-performance analysis. J. Mark. 41(1):77-79. https://doi.org/10.2307/1250495

Meason, G.L. 1828. On the landscape architecture of the great painters of Italy (1st ed.). London, England: D. Jaques.

Mintz, S. and S. Rode. 1999. More than a walk in the park?: Demonstration carts personalize interpretation. Roots 18:24-26.

Oh, H.M. 2001. Revisiting importance-performance analysis. Tour. Manag. 22(6):617-627. https://doi.org/10.1016/S0261-5177(01)00036-X

Olmsted, F.L. 1852. Walks and talks of an American farmer in England. New York, NY: George P. Putnam.

Willison, J. 1997. Botanic gardens as agents for social change. In: Conservation into the 21st century (pp. 339-344). Proceedings of the fourth International Botanical Gardens Conservation Congress, 25-29 September, 1995, Perth, Australia: Kings Park and Botanic Garden West Australia.

Wyse Jackson, P.S. and L.A. Sutherland. 2000. International agenda for botanic gardens in conservation (pp. 12-14). Surrey, England: Botanic Gardens Conservation International. 